Ethnicity and Health Unit, NIHR Applied Research Collaboration Northwest London, London, UK

2 Department of Primary Care and Public Health, School of Public Health, Imperial College London, London, UK

3 Centre for Implementation Science, Health Service and Population Research Department, King's College London, London, UK

4 NIHR Applied Research Collaboration South London at King's College Hospital NHS Foundation Trust, London, UK

5 Centre for Perinatal Neuroscience, Department of Brain Sciences, Faculty of Medicine, Imperial College London, London, UK

Correspondence to: $\mathrm{M}$ Rao mala.rao@imperial.ac.uk Cite this as: BMJ 2022;376:e065574 http://dx.doi.org/10.1136/bmi-2021-065574 Published: 18 January 2022

\section{Tackling racism in UK health research}

Richard A Powell and colleagues set out the barriers and solutions to eliminating inequalities embedded in the UK health research system

\author{
Richard Antony Powell, ${ }^{1,2}$ Chidi Njoku, ${ }^{1,2}$ Ramyia Elangovan, ${ }^{3}$ Ganesh Sathyamoorthy, ${ }^{1,2}$ Josephine Ocloo, ${ }^{3}$ \\ ${ }^{4}$ Sudhin Thayil, ${ }^{5}$ Mala Rao, 2
}

Seismic forces are challenging the UK's ethno-racial status quo. ${ }^{12}$ As a result, many organisations have made public commitments to listen to, learn from, and act on factors sustaining historical and current ethno-racial injustices and inequalities.

The UK health research landscape, with its vast influence on national and global strategy for health and wellbeing, has an opportunity and responsibility to advance a transformative, equity based agenda for change. ${ }^{3}$ Racism is currently present throughout UK health research, including commissioning and implementation (both ostensibly underpinned by patient and public involvement), assessment, and dissemination, and we propose actions to produce systemic change. We use an equity approach that moves beyond creating an "equal, level playing field" and instead treats the unequal unequally. ${ }^{4}$

Our analysis is based on an understanding of racism as "the normalisation and legitimisation of an array of dynamics-historical, cultural, institutional, and interpersonal-that routinely advantage white people while producing cumulative and chronic adverse outcomes for people of colour," 5 based on their physiological appearance or cultural identity (ethnicity). The intersection between ethnicity, race, and health is a product of this systemic discrimination, in which racism-a social construct-not ethnicity causes health disparities. ${ }^{67}$ However, reducing racism in health research infrastructure will not in itself solve population health problems. We use the descriptors "racialised minorities," ${ }^{8}$ recognising that disadvantage is not uniform among different minority groups, and "ethno-racial" to refer to the phenotype, ancestry, and self-identification of ethnic and racial groups. ${ }^{9}$

\section{Racism in research commissioning}

The setting of research agendas may seem a racially neutral, objective process, but in reality these agendas are influenced by multiple potential biases. ${ }^{10}$ The leadership of research commissioning bodies drives the research agenda, determining how questions are framed, what data informs them, and how patients and the public are involved. For example, questions can be framed to imply a "black deficit" (eg, what causes black people to have so many disadvantages compared with white people?), which places the culpability of individuals over structural failures and histories of exclusion. ${ }^{11}$

Although inclusion of minority groups in leadership roles does not guarantee positive change, ${ }^{12}$ evidence from other sectors suggests ethno-racial diversity has substantial benefits, ${ }^{13}$ including a richer pool of critical ideas, innovation, and entrepreneurship. ${ }^{1415}$ Diversity also ensures that the workforce and cultural competence of an organisation better reflect changing population mix, and are able to meet the needs of all stakeholder communities. ${ }^{16}$ Yet, data on the ethno-racial diversity of commissioning leadership teams is scant at best: the Wellcome Trust is one of very few research organisations to have provided information, acknowledging publicly that all members of its executive team are white. ${ }^{17}$

Similarly exclusionary is the historical under-representation of racialised minority populations as participants in UK research despite comparatively worse rates of ill health. ${ }^{18}$ For example, the underdetection of hypoxaemia by pulse oximetry ${ }^{19}$ and the underdiagnosis of melanomas by cancer software ${ }^{20}$ in black patients result from white patients being used as the default group in the algorithms used to develop and test these medical devices. Another example is the poorly evidenced, racially tailored care that can perpetuate harmful and unscientific ideas about biological differences between people of different ethnicities. These ideas persist in the medical guidelines that inform treatment decisions, ${ }^{21}$ driving medical errors and increasing health inequities. ${ }^{22}$ The current UK guidance on treating high blood pressure, for example, recommends angiotensin converting enzyme inhibitors for everyone except people of "Black African or Black Caribbean heritage," who are recommended calcium channel blockers initially. ${ }^{23}$

Despite growing acknowledgement of the harmful implications of these anomalies in medical decision making and technology, research commissioners are failing to invest the resources required to ensure that devices work accurately across ethno-racial groups, and that treatment and care are not based on poor evidence, historical assumptions, and stereotypes. The interests and concerns of minorities must be represented in research planning and prioritisation.

The paucity of data on racialised minorities is itself a barrier to a diverse academic workforce and, by extension, to inclusive health research. In the Medical Research Council's survey of research fellowships, data on the ethnicity and nationality of fellows were "very limited." 24 The recent release of data showing the diversity of applicants for and recipients of funding from the National Institute for Health Research (NIHR) showed that racialised minority applicants were less successful than white applicants (16.5\% success rate $v 21.2 \%$ for white applicants). This helps to fill the data gap, but NIHR recognises that 
more work is needed to track, report, and evaluate diversity throughout research organisations. ${ }^{25}$

The absence of routinely collected and reported information undermines our understanding of the extent of biases in the research workforce. When data are reported, racialised minorities are often aggregated into one group, obscuring differences among distinct ethnicities. ${ }^{26}$

Two decades ago, the seminal Stephen Lawrence inquiry in the UK triggered reflection on the need for better health related data, recommending that ethnic group rather than country of birth should be recorded on death certificates. ${ }^{27}$ Problems associated with unreliable proxy measures of ethno-racial affiliation were highlighted again early in the covid-19 pandemic, preventing timely understanding of the virus's differential effect on mortality, and delaying equity based remedial measures.

\section{Patient and public involvement}

Patient and public involvement in research is important because it can influence the research questions asked and the outcomes measured. Patients and the public can ensure that researchers measure outcomes that matter to them and their communities, improving the validity of data and the value of research findings. ${ }^{28}$

Racialised minority groups are also under-represented in patient communities recruited to research. Consequently, their participation in research studies is inadequate, ${ }^{29-31}$ including in covid-19 vaccine trials. ${ }^{32}$ As others have said, "omission has consequences: people could miss out on important benefits or not be spared harms ... there is no guarantee that the results will apply to populations not included in the research." ${ }^{2}$ Omission could also reinforce existing social injustices and health inequalities. Box 1 lists some measures to help eradicate racism in research commissioning

\section{Box 1: Potential solutions to racism in research}

- Include ethno-racial equity in all policies and decisions influencing the research commissioning agenda

- Monitor and improve racialised minority representation in research commissioning leadership roles, on key committees and panels, and in patient and public communities involved in research

- Quantify, report, and resolve variations in research funding, starting with reliable data on funding awards, stratified by ethno-racial group, as the NIHR has started to do 25

- Prioritise research questions and outcomes of greatest importance to specific ethno-racial groups

- Establish financial incentives to improve diversity in research institutions by developing criteria modelled on the Athena SWAN Charter ${ }^{33}$ (linked to improving gender equality in academia), as a condition of NIHR funding

\section{Racism in academia}

Academics are responsible for implementing the research agenda and training the next generation of researchers, yet negative experiences are becoming normalised in a culture of silent acceptance. ${ }^{34}$ In 2019, 24\% of racialised minority university students reported experiencing racial harassment, 35 but, for example, only half of medical schools collected data on their complaints. ${ }^{36}$

Racialised minority applicants are less likely than white applicants to be awarded funding grants by the UK's Wellcome Trust ${ }^{17}$ and are under-represented among UK Research and Innovation (UKRI) fellows and principal investigators, ${ }^{26}$ echoing US funding differentials among African-American or black principal investigators. ${ }^{37}$

The mechanisms by which the academic environment and structures reinforce existing inequities are complex, but core challenges include lack of diversity in executive leadership, ethno-racial discordance between students and teachers, unsupportive "soft learning” environments, and poorer research funding for racialised minority academics.

The executive leadership of all major UK medical schools is overwhelmingly white, ${ }^{38}$ while $41 \%$ of medical students are from racialised minorities. ${ }^{39}$ Such snowy white peaks at university potentially foster a networked club culture in which access to senior leadership positions can exclude racialised minority academics. Moreover, evidence suggests ethno-racial concordance between students and teachers benefits learning and achievement in medical and other disciplines. 4041

Despite being selected for academic achievement, medical students from minority backgrounds perform worse educationally on average than white peers in the UK. ${ }^{42}$ One explanation lies in the learning experience. Learning is an interactive social process between students, teachers, and peers, but these processes are patterned by ethnicity. ${ }^{43}$ Learning environments must also be supportive and celebrate difference, a process aided by greater ethno-racial diversity among academics. In 2019, racialised minorities accounted for $22 \%$ of lecturers, readers, and senior lecturers in medical schools, but only $14 \%$ of medical professors. 44

Those charged with tackling these inequities could learn from the NHS, where the Workforce Race Equality Standard (WRES) 45 and, more recently, the Medical Workforce Race Equality Standard (MWRES) ${ }^{46}$ have been collecting data on race inequality since 2015, holding up a mirror to the service and revealing disparities in career progression, experience, and opportunities that exist for people from racialised minorities compared with white staff. Although change may be slow, data collection has increased awareness and action to tackle many dimensions of structural racism in medicine, ranging from recruitment to bullying, education, and training. Importantly, it has resulted in modest but demonstrable improvements, including a small increase in the diversity of NHS "very senior managers" and trust board membership across England since 2017.45

Indicators should be developed to monitor the recruitment, career progression, experience, and achievements (including funding awards) of academics and researchers from racialised minority groups. Strategies must also be developed to address any disparities exposed by these indicators, drawing on lessons from the response to WRES and MWRES in the NHS.

\section{Racism in assessment of research excellence}

A UK university's research performance is appraised and ranked every six years using a system called the research excellence framework. The 2021 round of assessments-delayed by the pandemic-includes a measure of diversity and equality as part of the evaluation of "the vitality and sustainability of a university's research environment." However, it remains unclear what proportion of the overall environment score-which accounts for only $15 \%$ of a university's overall assessment-will be determined by equality and diversity. ${ }^{47}$ Furthermore, equality and diversity are assessed from written submissions. There is no requirement for data on how minorities experience a university environment, despite evidence that equality and diversity strategies correlate poorly with 
actual working conditions and progression for women and minorities..$^{48}$

The UK's research excellence framework should be reformed to improve assessment of ethno-racial equity within universities, for both workforce and students. Importantly, academics and students from racialised minorities should be full partners in the design and implementation of these reforms. Related frameworks from other countries, including the US-where the National Institutes of Health seek to tackle structural racism and promote racial equity and inclusion internally and within the larger biomedical research enterprise ${ }^{49}$-could inform this process.

The ultimate goal is a more effective multidimensional assessment of research performance that does full justice to the importance of diversity, inclusion, and ethno-racial equity based on a dataset agreed by all stakeholders.

\section{Racism in research dissemination}

Substantial evidence exists of widespread ethno-racial bias in academic publishing. ${ }^{50-53}$ In the US, journals have been criticised for denying ethno-racial bias, refusing to publish research identifying racism, 54 and recruiting and tolerating overwhelmingly white editorial boards. ${ }^{55}$ In the UK, Nature has acknowledged that it is "one of the white institutions ... responsible for bias in research and scholarship," declaring that science "has been-and remains-complicit in systemic racism." ${ }^{6} 6$ Similarly, the Lancet described itself as having "a deep colonial history." 57

It is important for journals to show a commitment to equity. Journal editors are powerful gatekeepers, determining what gets reviewed (by whom) and published, and publications matter. Publications and other academic outputs account for $60 \%$ of the overall score of institutions in the latest research excellence framework. ${ }^{47}$ For academics, journal publications, membership of editorial boards, and invitations to review papers are key measures of success and requirements for career progression. Publications are also important for securing research funding; developing the analytical, reviewing, and writing skills of trainees; and disseminating knowledge and research.

The potential power of journals to effect change in key societal issues was shown by The BMJ's 2020 themed issue on racism in medicine, ${ }^{58}$ which substantially contributed to the subsequent decision to launch an NHS Race and Health Observatory. ${ }^{59}$ In recognition of the role of journals in embedding justice and equity in research and scholarly communication, The BMJ has pledged a commitment to equality, diversity, and inclusion, ${ }^{60}$ as have others. ${ }^{56} 57$ Stated commitments of high impact journals to address inherent biases in the publication process, improve the publication chances of racialised minorities, and increase the publication of ethno-racial research are welcome. But journals could and should be more ambitious, committing to measurable targets and timetables to achieve justice and equity for under-represented groups. Journals could start by publishing regular data on the diversity of their authors, reviewers, and editorial boards. They could also audit and publish the proportion of content dedicated to ethno-racial research.

\section{Commitment to change}

For too long health research architecture in the UK has been guilty of reinforcing instead of reducing systemic ethno-racial inequities, fortifying "persistent, pervasive racism that exists across societies."61 Stakeholders in the UK must change their structures, systems, and processes to reflect the diversity of the population, optimise innovation, and inform inclusive decision making. ${ }^{62}$ They must implement a transformative, anti-racist, equity based research agenda. By committing to this agenda, we can make substantive and permanent change tackling the structural determinants of health inequalities.

\section{Key messages}

- Racism is evident across the UK health research landscape, from funding bodies through to peer reviewed journals

- UK organisations are beginning to listen to, learn from, and act on factors maintaining historical ethno-racial injustice and social inequity

- Stakeholders must collectively commit to improving equity, diversity, and inclusion in health research, by changing structures, systems, and processes

- Ethno-racial equity requires a research community determined to ensure that health research does not reinforce and exacerbate existing health and social inequities

Contributors and sources: The authors have experience advocating for change in the UK NHS and research funding agencies. MR, GS, CN, ST, and JO have experienced ethno-racial discrimination within and outside academia, and $\mathrm{JO}$ is also a patient and public involvement representative and lived experience researcher. RAP has researched and commented on services received by, and provided to, people from racialised minority communities in the UK and diverse ethnic populations internationally. The article is based on peer reviewed publications, grey literature, and primary data collection by the authors. MR conceived this article. RAP initially drafted the paper, with all co-authors reviewing and contributing to its revision and finalisation. MR is the guarantor.

Competing interests: We have read and understood BMJ policy on declaration of interests and have no relevant interests to declare. The views expressed are those of the authors and not necessarily those of the NHS, the NIHR, or the Department of Health and Social Care.

Provenance and peer review: Not commissioned; externally peer reviewed.

Gottbrath L-W. The Black Lives Matter movement shook the world. Al Jazeera 2020 Dec 31. https://www.aljazeera.com/features/2020/12/31/2020-the-year-black-lives-matter-shook-theworld

2 Karan A, Katz I. There is no stopping covid-19 without stopping racism. BMJ2020;369:m2244. doi: 10.1136/bmj.m2244 pmid: 32518097

Mooney GH. Equity in health care: confronting the confusion. Eff Health Care 1983;1:179-85.pmid: 10310519

West PA. Theoretical and practical equity in the National Health Service in England. Soc Sci Med 1981;15:117-22.

Lawrence K, Keleher T. Structural racism. Race and Public Policy Conference, 2004

https://www.intergroupresources.com/rc/Definitions\%20of\%20Racism.pdf.

Gravlee CC. How race becomes biology: embodiment of social inequality. Am J Phys Anthropol 2009;139:47-57. doi: 10.1002/ajpa.20983 pmid: 19226645

Wallis C. Why racism, not race, is a risk factor for dying of covid-19. Scientific American 2020 Jun 12. https://www.scientificamerican.com/article/why-racism-not-race-is-a-risk-factor-for-dying-of covid-191/

8 Gabriel D. Racial categorisation and terminology. Black British Academics. https://blackbritishacademics.co.uk/about/racial-categorisation-and-terminology/

9 Paredes CL. Multidimensional ethno-racial status in contexts of mestizaje: ethno-racial stratification in contemporary Peru. Socius 2018;(January). doi: 10.1177/2378023118762002

10 Hug SE, Aeschbach M. Criteria for assessing grant applications: a systematic review. Palgrave Publications 2020;6:37. doi: 10.1057/s41599-020-0412-9

11 Hardeman RR, Karbeah J. Examining racism in health services research: a disciplinary self-critique Health Serv Res 2020;55(Suppl 2):777-80. doi: 10.1111/1475-6773.13558 pmid: 32976632

12 Razai MS, Majeed A, Esmail A. Structural racism is a fundamental cause and driver of ethnic disparities in health. BMJ Opinion, 31 Mar 2021. https://blogs.bmj.com/bmj/2021/03/31/structuralracism-is-a-fundamental-cause-and-driver-of-ethnic-disparities-in-health/

13 Hunt V, Prince S, Dixon-Fyle S, Dolan K. Diversity wins: how inclusion matters. 2020. https://www.mckinsey.com/ /media/McKinsey/Featured\%20Insights/Diversity\%20and\%20Inclusion/Diversity\%20wins\%20How\%20inclusion\%20matters/Diversity-wins-How-inclusionmatters-vF.pdf

14 Nathan M, Lee N. Cultural diversity, innovation and entrepreneurship: Firm-level evidence from London. Econ Geogr 2013;89:367-94doi: 10.1111/ecge.12016

15 Rock D, Grant H. Why diverse teams are smarter. Harvard Business Review 2016 Nov 4. https://hbr.org/2016/11/why-diverse-teams-are-smarter

16 Feyes E. Leadership and the promotion of diversity in the work force and beyond. In: Huber T, Breitenstine L, Shreber L, Budzik K, Moffitt T, Persol J, eds. Leadership lessons in healthcare and public health. Ohio State University Pressbooks, 2018: 81-8.

17 Wellcome Trust. Our commitment to tackling racism at Wellcome. Press release, 17 Jun 2020. https://wellcome.org/press-release/our-commitment-tackling-racism-wellcome 
18 Nazroo J. Addressing inequalities in healthy life expectancy. Future of an ageing population: evidence review. Government Office for Science, 2015.

19 Sjoding MW, Dickson RP, Iwashyna TJ, Gay SE, Valley TS. Racial bias in pulse oximetry measurement. N Engl J Med 2020;383:2477-8. doi: 10.1056/NEJMc2029240 pmid: 33326721

20 Noor P. Can we trust Al not to further embed racial bias and prejudice?BMJ2020;368:m363 doi: 10.1136/bmj.m363 pmid: 32051165

21 Liverpool L, Tsai J. Medicine must stop using race and ethnicity to interpret test results. New SC 2021:10. doi: 10.1016/S0262-4079(21)00761-2

22 Cerdeña JP, Plaisime MV, Tsai J. From race-based to race-conscious medicine: how anti-racist uprisings call us to act. Lancet 2020;396:1125-8. doi: 10.1016/S0140-6736(20)32076-6 pmid: 33038972

23 Gopal DP, Okoli GN, Rao M. Re-thinking the inclusion of race in British hypertension guidance. J Hum Hypertens 2021. doi: 10.1038/s41371-021-00601-9. pmid: 34508156

24 Medical Research Council. 2017 UK-wide survey of clinical and health research fellowships. Medical Research Council, 2017

25 National Institute of Health Research. Diversity data report 2020-21. 2021. https:/www.nihr.ac.uk/documents/diversity-data-report-202021/29410

26 UK Research and Innovation. Diversity results for UKRI funding data: 2014-15 to 2018-19. 2020. https://www.ukri.org/publications/diversity-results-analysis-for-ukri-funding-data-financial-years2014-15-to-2018-19/

27 McKenzie K. Something borrowed from the blues?BMJ 1999;318:616-7. doi: 10.1136/bmj.318.7184.616 pmid: 10066181

28 Palmer-Cooper E. Public involvement in research-just good science. Psychologist2018;31:46-7.

29 Ocloo J. Being heard, not, "seldom heard": democratising research with diverse communities during the covid-19 pandemic. BMJ Opinion, 2 Jun 2020. https://blogs.bmi.com/bmi/2020/06/02/being-heard-not-seldom-heard-democratising-researchwith-diverse-communities-during-the-covid-19-pandemic

30 Ocloo J, Matthews R. From tokenism to empowerment: progressing patient and public involvement in healthcare improvement. BMJ Qual Saf 2016;25:626-32 doi: 10.1136/bmjqs-2015-004839 pmid: 26993640

31 Khan S, Mian A. Racism and medical education. Lancet Infect Dis 2020;20:1009. doi: 10.1016/S1473-3099(20)30639-3 pmid: 32860760

32 Treweek S, Forouhi NG, Narayan KMV, Khunti K. Covid-19 and ethnicity: who will research results apply to? Lancet 2020;395:1955-7. doi: 10.1016/S0140-6736(20)31380-5 pmid: 32539937

33 Advance HE. Athena Swan Charter. https:/www.advance-he.ac.uk/equality-charters/athenaswan-charter

34 Wong B, Elmorally R, Copsey-Blake M, Highwood E, Singarayer J. Is race still relevant? Student perceptions and experiences of racism in higher education. Camb J Educ 2021;51:359-75doi: 10.1080/0305764X.2020.1831441.

35 Equality and Human Rights Commission. Racial harassment inquiry: survey of university students. Research report No. 129. Equality and Human Rights Commission, 2019.

36 Kmietowicz Z. Are medical schools turning a blind eye to racism?BMJ2020;368:m420. doi: 10.1136/bmj.m420 pmid: 32051116

37 Taffe MA, Gilpin NW. Racial inequity in grant funding from the US National Institutes of Health Elife 2021;10:e65697. doi: 10.7554/eLife.65697 pmid: 33459595

38 Park G. The colour of power. Green Park, 2020. https://www.green-park.co.uk/insights/the-colourof-power/s191468/

39 General Medical Council. Number of medical students per medical school by ethnicity in UK for 2016/2017. https://www.gmc-uk.org/-/media/documents/201617_Medical_SchooL_Annual_Return_overall_student_numbers_and_demographics.xlsx_71843956.xlsx

40 Woolf K. Differential attainment in medical education and training. BMJ2020;368:m339. doi: 10.1136/bmj.m339 pmid: 32047006

41 Brown LI. Diversity: the challenge for higher education. Race Ethn Educ 2004;7:21-34.doi: 10.1080/1361332042000187289

42 Woolf K, Potts HWW, McManus IC. Ethnicity and academic performance in UK trained doctors and medical students: systematic review and meta-analysis. BMJ 2011;342:d901. doi: 10.1136/bmj.d901 pmid: 21385802

43 Woolf K, Potts HWW, Patel S, McManus IC. The hidden medical school: a longitudinal study of how social networks form, and how they relate to academic performance. Med Teach 2012;34:577-86. doi: 10.3109/0142159X.2012.669082 pmid: 22746963

44 Medical Schools Council. Clinical academic survey, 2019. https://www.medschools.ac.uk/clinicalacademic-survey

45 NHS. Workforce race equality standard. 2020 data analysis report for NHS Trusts and clinical commissioning groups. NHS, 2021. https://www.england.nhs.uk/wp-content/uploads/2021/02/Workforce-Race-Equality-Standard-2020-report.pdf

46 NHS. Medical workforce race equality standard. WRES indicators for the medical workforce 2020 2021. https://www.england.nhs.uk/publication/medical-workforce-race-equality-standard-2020data-report/

47 Obasi Al. Equity in excellence or just another tax on Black skin? Lancet 2020;396:651-3. doi: 10.1016/S0140-6736(20)31536-1 pmid: 32711686

48 Khan MS, Lakha F, Tan MMJ, etal. More talk than action: gender and ethnic diversity in leading public health universities. Lancet 2019:393:594-600. doi: 10.1016/S0140-6736(18)32609-6 pmid: 30739695
49 National Institutes of Health. Ending structural racism. https://www.nih.gov/ending-structuralracism.

50 Pan RK, Kaski K, Fortunato S. World citation and collaboration networks: uncovering the role of geography in science. Sci Rep 2012;2:902. doi: 10.1038/srep00902 pmid: 23198092

51 Harris M, Macinko J, Jimenez G, Mullachery P. Measuring the bias against low-income country research: an implicit association test. Global Health 2017;13:80. doi: 10.1186/s12992-017-0304-y pmid: 29110668

52 Harris M, Marti J, Watt H, Bhatti Y, Macinko J, Darzi AW. Explicit bias toward high-income-country research: A randomized, blinded, crossover experiment of English clinicians. Health Aff (Millwood) 2017;36:1997-2004. doi: 10.1377/hlthaff.2017.0773 pmid: 29137509

53 Sharma D. A call for reforms in global health publications. Lancet Glob Health 2021;9:e901-2. doi: 10.1016/S2214-109X(21)00145-5 pmid: 34143988

54 Krieger N, Boyd RW, De Maio F, Maybank A. Medicine's privileged gatekeepers: producing harmfu ignorance about racism and health. Health Affairs blog, 20 Apr 2021. https://www.healthaffairs.org/do/10.1377/hblog20210415.305480/full/.

55 McFarling UL. When a cardiologist flagged the lack of diversity at premier medical journals, the silence was telling. STAT 2021 Apr 12. https://www.statnews.com/2021/04/12/lack-of-diversity at-premier-medical-journals-jama-nejm/

56 Systemic racism: science must listen, learn and change. Nature 2020;582:147. doi: 10.1038/d41586-020-01678-x pmid: 32518347

57 Editors of The Lancet Group. The Lancet Group's commitments to gender equity and diversity. Lancet 2019;394:452-3. doi: 10.1016/S0140-6736(19)31797-0 pmid: 31402014

58 Racism in medicine (special edition). BMJ2020;368 (13 Feb). https://www.bmi.com/racism-inmedicine.

59 Kmietowicz Z. NHS launches race and health observatory after BMJ's call to end inequalities. BMJ 2020;369:m2191.

60 Richards M, Franco J, Bloom T. A commitment to equality, diversity and inclusion for BMJ and our journals. BMJ Opinion, 23 Jul 2021. https://blogs.bmj.com/bmi/2021/07/23/a-commitment-toequality-diversity-and-inclusion-for-bmj-and-our-journals/.

61 Lancet. Medicine and medical science: black lives must matter more. Lancet 2020;395:1813. doi: 10.1016/S0140-6736(20)31353-2 pmid: 32534634

62 Adebowale V, Rao M. Racism in medicine: why equality matters to everyone. BMJ 2020;368:m530. doi: 10.1136/bmi.m530 pmid: 32051166

This is an Open Access article distributed in accordance with the Creative Commons Attribution Non Commercial (CC BY-NC 4.0) license, which permits others to distribute, remix, adapt, build upon this work non-commercially, and license their derivative works on different terms, provided the original work is properly cited and the use is non-commercial. See: http://creativecommons.org/licenses/by$\mathrm{nc} / 4.0 \%$. 